\title{
DO CENTRO ÀS PERIFERIAS: 0 DESLOCAMENTO IDEOLÓGICO DA DIPLOMACIA DA SANTA SÉ COM O PAPA FRANCISCO
}

\section{Anna Carletti ${ }^{1}$}

\section{Introdução}

Com o fim do sistema bipolar teve início um reordenamento das relações de forças em âmbito internacional devido principalmente ao surgimento de novos atores, na sua maioria, provenientes da assim chamada periferia do mundo. Após 500 anos de supremacia ocidental, os antigos centros de poder - entre os quais se destaca a China - parecem estar voltando ao cenário internacional pedindo uma inclusão qualitativa e não apenas quantitativa dentro do sistema internacional, como a que ocorreu após os processos de descolonização da Ásia e África. Trata-se de uma demanda de reestruturação internacional que leve em conta as mudanças ocorridas neste âmbito desde o fim da Segunda Guerra Mundial.

É neste cenário que surge o pontificado de Francisco, primeiro papa não europeu e primeiro papa latino-americano. O novo chefe do maior e mais influente ator religioso transnacional parece ter inaugurado um novo estágio de atuação da Igreja Católica no mundo, caracterizado por um deslocamento ideológico menos eurocêntrico e mais favorável à emergência das periferias, em sintonia com a atual demanda de reestruturação do sistema internacional apresentada por parte das nações periféricas. Através de uma leitura internacional dos primeiros anos de pontificado de Francisco, associada à análise do contexto mundial e regional - com especial ênfase na conjuntura da América Latina - que o precedeu, buscar-se-á, nesta pesquisa, evidenciar a importância

\footnotetext{
I Doutora em História e Pós-Doutora em Ciência Política pela UFRGS e Docente do curso de Relações Internacionais da Universidade Federal do Pampa. E-mail: annacarlettib@hotmail. com
} 
do papel que a Santa Sé pode desempenhar neste atual momento de reconfiguração mundial, não apenas em âmbito religioso, como também político.

Tal estudo busca contribuir também para a construção de novas categorias conceituais aptas a explicar a noção de ator religioso transnacional e sua atuação no âmbito de um sistema internacional considerado pela maioria das teorias de relações internacionais como um sistema secularizado e com pouco espaço para o fenômeno religioso.

$\mathrm{Na}$ primeira parte do artigo, vamos analisar o impacto da presença dos atores transnacionais religiosos no contexto do atual sistema internacional em transição dedicando especial atenção ao maior ator religião transnacional: a Igreja Católica.

$\mathrm{Na}$ segunda parte, serão analisadas as mudanças ocorridas de 2013 ao início de 2015 na composição e reestruturação da Cúria Romana, e, em seguida, alguns discursos e documentos do Papa Francisco e de seu novo Secretário de Estado enfatizando os que parecem ser os pontos-chave da nova diplomacia de Francisco.

Através dessa análise, procuraremos verificar a hipótese de que, nestes dois primeiros anos do pontificado, o Papa Francisco parece estar realizando um deslocamento ideológico da Santa Sé, aproximando a estrutura central da Igreja Católica, tradicionalmente ligada às elites nacionais e internacionais, às periferias do mundo político e eclesial.

\section{0 impacto dos atores transnacionais religiosos no atual sistema internacional: o caso da Igreja Católica}

Antes de falar do impacto dos atores religiosos transnacionais no atual sistema internacional faz-se necessária uma breve premissa para entendermos em que contexto tais atores religiosos ganharam relevância no cenário internacional e o porquê deste seu "inesperado" ressurgimento após séculos de aparente silêncio.

Com efeito, os acordos de Westfália, em i648, que marcaram o fim das longas guerras de religião na Europa, consagraram o princípio norteador da nova ordem internacional. A aplicação do principio cuius regio eius religio deveria garantir que, daquele momento em diante, a política dos Estados ficaria isenta de qualquer conotação religiosa. De fato, a política ligada à religião se tornou sinônimo de ameaça certa para a ordem, para segurança e para racionalidade. Era preciso, portanto, bani-la do âmbito público. Política e Religião "não poderiam coexistir nas práticas das relações internacionais" (Petito and Hatzopolous 2003, 2). As religiões perderam então sua influência em 
âmbito internacional. Os Estados nacionais foram considerados a partir de então os únicos atores capazes de influenciar a dinâmica das relações internacionais. Quando do surgimento das primeiras vertentes teóricas das relações internacionais, os Estados-nação ainda ocupavam um lugar de proeminência mesmo se começava a ser reconhecida a importância da atuação de outros possíveis atores internacionais. Contudo, o fenômeno religioso continuava sendo ignorado ou até rejeitado pelas teorias das relações internacionais que se desenvolveram a partir dos anos do entre guerras.

Nas últimas décadas, porém, registrou-se um ressurgimento do fenômeno religioso que suscitou, ao mesmo tempo, surpresa e interesse entre os analistas de política internacional. A partir do final da década de I980, e, sobretudo, após os acontecimentos do dia II de setembro de 200I, a análise do fenômeno religioso no âmbito dos estudos de política internacional vem conquistando mais espaço. O fator "esquecido", usando a expressão de Petito e Hatzopolous (2003), parece ter voltado do exílio, sendo considerado atualmente, por alguns analistas (Dosdad 2006; Ferrara 20I4), entre os elementos-chave cuja compreensão poderia auxiliar numa análise mais ampla e profunda dos eventos mundiais e do mundo em transformação.

No âmbito desta reavaliação da importância do fenômeno religioso, ao lado dos atores estatais e não estatais reconhecidos tradicionalmente como agentes influenciadores das dinâmicas internacionais, destacam-se de forma cada vez mais proeminente também os atores transnacionais religiosos que, de acordo com Haynes (2009), indubitavelmente afetam tanto a política interna que a política internacional dos Estados. Ao lado dos movimentos evangélicos norte-americanos, outros atores religiosos transnacionais são os movimentos islâmicos moderados ou extremistas, grupos nacionalistas hindus, fundamentalistas judeus, a Igreja Católica, entre outros.

Tais atores transnacionais religiosos possuem em comum a capacidade de atuar nas relações internacionais interagindo com grupos que possuem metas semelhantes e ultrapassando os limites estatais visam alcançar seus interesses vitais. Isso é possível apenas pela realidade atual da sociedade globalizante onde as barreiras de comunicação diminuíram e as redes nacionais em nível global não encontram grandes obstáculos, o que potencializa as capacidades destes atores transnacionais de ultrapassar as fronteiras dos Estados Nacionais e se tornar forças significativas que podem contribuir para moldar os acontecimentos internacionais (Haynes 2009).

Entre os maiores atores religiosos transnacionais, a Santa Sé e consequentemente a Igreja Católica Romana, contando com mais de I bilhão de fiéis no mundo todo, destaca-se no cenário internacional principalmente por possuir 
(...) uma ligação especial entre autoridade espiritual e autoridade temporal, pela combinação entre a organização de uma religião e a estrutura de um estado, pela superposição entre o sagrado e o soberano. O papa é ao mesmo tempo Somo Pontífice da Igreja e Poder Executivo do Estado do Vaticano (Turzi 2013, 30).

A Santa Sé, o órgão de governo da Igreja Católica é a única instituição religiosa no mundo que tem a prerrogativa de manter relações diplomáticas com os Estados. Atualmente, a Santa Sé possui representantes diplomáticos em I77 países além de manter observadores permanentes em organismos internacionais, como a Organização das Nações Unidas, entre outras.

Mesmo sendo considerado um Estado com todas as características constitutivas desta instituição política, a Santa Sé permanece um ator estatal sui generis. Os interesses que a Santa Sé persegue não são econômicos nem militares. Mesmo tendo dois corpos de segurança: os Guardas Suíços e o corpo de Gendarmaria ${ }^{2}$, a Santa Sé não possui os tradicionais recursos de poder do Hard Power, que qualificam a importância de um país no cenário internacional. Então, que tipo de relações de forças distingue a atuação da Santa Sé no cenário internacional?

Ao se utilizar o conceito de Joseph Nye acerca da força do Soft Power, definido como poder de atração e de convencimento ao invés de coerção ou recompensa, pode-se pensar que a Santa Sé tenha utilizado como base de sustentação de seu agir internacional justamente este tipo de poder, chamado poder brando, ou Soft Power descrito também como resultado de uma série de elementos de difícil mensuração, mas que envolvem diferentes dimensões.

A Santa Sé faz uso desse poder através de uma rede capilar de igrejas locais, instituições sociais e educativas distribuídas em todo o planeta. Sua mensagem é escutada mesmo pelos que não fazem parte desta instituição. Suas ações, positivas ou negativas repercutem nos meios de comunicação mundiais. Os escândalos financeiros e sexuais minaram a credibilidade e legitimidade da Igreja Católica, sobretudo nos últimos dois pontificados, o de João Paulo II e de Bento XVI. Papa Francisco, desde sua primeira aparição,

\footnotetext{
2 Ambos os Corpos tem a tarefa de defender o Estado da Cidade do Vaticano. Os Guardas Suíços têm suas origens em 1506 , quando foram recebidos como exército permanente pontifício pelo papa Júlio II. O Corpo da Gendarmaria foi criado sob o papa Pio VII, em I8ı6, abolido em I970, ressurgindo em I99I. Atualmente, o corpo de Gendarmaria, de uniforme azul, é constituído de cerca de Ioo agentes devidamente treinados, provenientes de repartições antiterroristas e que agem protegendo o papa e vigiando os ingressos nas portas dos muros vaticanos. Quando das viagens papais, cabe a eles a segurança do papa, em acordo com as autoridades da polícia do país que recebe a visita.
} 
parece buscar reestabelecer a credibilidade da Igreja perdida nas últimas décadas.

\section{As tentativas revolucionárias do primeiro papa latino- americano}

Desde a eleição do Papa Francisco muito se discutiu e muito se escreveu sobre a possível influência da proveniência geográfica do novo papa em relação ao futuro da Igreja Católica. Papa Francisco não é apenas o primeiro papa não europeu, mas também o primeiro papa latino-americano, isto é, um papa que nasceu, cresceu e viveu no sul do mundo, na periferia do poder tanto político e eclesial. Contudo, isto não seria um condicionamento suficiente para explicar os novos rumos que Francisco está empreendendo.

Um dos papáveis durante o conclave que elegeu o cardeal Bergoglio era também latino-americano, mas pertencente ao lado conservador da Igreja Católica. Então, o fato de ser latino-americano não explicaria completamente este deslocamento. Ao lado de sua latinidade, lembramos que Francisco é jesuíta. A Companhia de Jesus é uma das mais antigas ordens religiosas onde a componente comunidade, junto com estudo, obediência e discernimento é variável importante a ser considerada para entender a postura adotada por Bergoglio. O fato do Papa Francisco ter escolhido viver na Casa Santa Marta em contato de muitas pessoas, ao invés que residir no apartamento reservado ao papa - comparado por Francisco como um funil ao contrário, onde o acesso é estreito, e se entra com o conta-gotas (Spadaro 2013) - pode ser explicado justamente pela importância vital dada por Francisco à vida de comunidade. Outro elemento importante a ser considerado é sua experiência pastoral a frente de uma arquidiocese como a de Buenos Aires. Por isso escolhemos percorrer de forma introdutória a biografia do novo papa procurando colocar em evidência elementos que poderiam nos levar a uma compreensão mais clara das escolhas do novo papa.

\subsection{Notas Biográficas de Papa Francesco}

Papa Francisco - Jorge Maria Bergoglio - nasceu em I7 de dezembro de 1936 em Buenos Aires. Sua família - pai ferroviário, mãe dona de casa era originária da região do Piemonte (noroeste da Itália). Bergoglio, após ter ingressado no seminário diocesano, o deixou para se tornar jesuíta (Spadaro 20I3). Estudou teologia antes na Argentina, e depois na Alemanha onde conseguiu seu doutorado em Teologia. Após seu regresso na Argentina, foi 
nomeado provincial dos jesuítas (da Argentina e Paraguai), exercendo esta função de I973 a I979. Em I976, a junta militar chegou ao poder através de um golpe de Estado, instaurando um regime repressivo que durará até I983.

Bergoglio, como revelou em uma entrevista ao jesuíta Antonio Spadaro na revista "La Civiltà Cattolica", desempenhou a função de provincial sem ter tido nenhuma experiência anterior de como gerir uma comunidade. Quando assumiu o cargo, aos 36 anos, adotou uma postura autoritária que lhe procurou críticas e acusações de ultraconservadorismo. Contudo, graças àquela difícil experiência, quando anos depois foi nomeado Arcebispo de Buenos Aires, a atitude escolhida foi completamente diferente (Spadaro 2013).

Em I992, foi nomeado Bispo Auxiliar de Buenos Aires e em I998, Bergoglio foi nomeado Arcebispo de Buenos Aires. João Paulo II o criou cardeal em 200I. Entre 2005 e 20II, foi Presidente da Conferência Episcopal da Argentina. Como mencionado, desta vez a experiência de governo foi mais positiva que a de provincial. Aos 56 anos, Bergoglio aprendeu que "governar não era dar ordem, mas escutar, criar consenso, resolver problemas permitindo-se o tempo de avaliá-los com profundidade" (Politi 20I4, I39). Como arcebispo de Buenos Aires, privilegiou o estreito contato com os sacerdotes de sua diocese encorajando-os a praticar a misericórdia. Sua pastoral ficou conhecida pela sensibilidade aos problemas sociais.

Frequentemente, de ônibus ao invés que de carro, visitava as villas (os bairros mais pobres na grande Buenos Aires), participando das reuniões dos padres que trabalhavam com os mais pobres. Parava para conversar com os cartoneros, os que recolhiam o lixo na cidade de Buenos Aires. Bergoglio sentiu na pele os grandes problemas de uma metrópole com seu pluralismo cultural e suas contradições. Retratando as origens do novo papa, Politi evidencia a grande diferença do Papa Francisco em relação aos pontífices que o precederam:

Francisco é o primeiro papa nascido, crescido e que viveu numa metrópole contemporânea. $\mathrm{O}$ pontífice argentino, mesmo proveniente de uma área distante da Europa, é o único que se nutriu da experiência tumultuosa, dramática e variegada de uma cidade gigantesca, ao redor da qual gravitam treze milhões de habitantes. Ratzinger, Roncalli, Wojtyla e Luciani são todos nascidos em cidadezinhas de província e mesmo durante suas carreiras ignoraram o ritmo da metrópole (Politi 20I4, I40).

O contato diário com o povo argentino - ele preferiu morar num pequeno monolocal ao invés que na residência episcopal - incentivou seu empenho, como arcebispo, de combater as desigualdades sociais, denunciando 
abertamente aqueles que ele considerava responsáveis pelo sofrimento do povo, entre estes o governo argentino do Nestor Kirchner. Tal postura, se por um lado aumentou sua popularidade entre o povo, de outro lhe causou bastantes problemas com as autoridades políticas. Com efeito, já no final de 20Iо, o cardeal Bergoglio foi publicamente apontado como "colaboracionista" durante a ditadura militar. Os relatos difundidos pelos principais jornais de Buenos Aires - alinhados ao governo Kirchner - indicavam que Bergoglio, em i976, quando provincial dos jesuítas, teria traído dois sacerdotes de sua ordem, Yorio e Jalics, que foram presos e torturados. Uma vez soltos, os dois sacerdotes se refugiaram em Roma, acolhidos pelo Superior Geral dos Jesuítas, Pedro Arrupe, permanecendo no silêncio por muitos anos e deixando esta dúvida sobre a atitude de Bergoglio pairando no ar até sua eleição. De acordo com Frattini (20I4), os jornais próximos ao governo Kirchner preocuparam-se em alimentar esta dúvida que veio a tona de novo após a eleição de Bergoglio como novo Papa. Somente então, o silêncio de um dos dois sacerdotes foi quebrado. Padre Jalics vive atualmente na Alemanha, e após a eleição de Bergoglio afirmou que eles não foram traídos pelo então provincial. De acordo com suas informações, ele nunca os denunciou. Haviam acreditado nisso até o final dos anos 90 quando graças a conversações que eles tiveram entenderam qual era a verdade.

A visita da presidente Cristina Kirchner em I8 de março de 20I3, logo após sua eleição foi interpretada como sinal de trégua entre Bergoglio e o governo argentino.

\subsection{Os primeiros passos da Reforma da Cúria Romana, do Papado e da Igreja Católica}

Durante as reuniões pré-conclave das congregações gerais ocorridas de 4 a II março de 2013 , três propostas ganharam a aprovação dos cardeais: reformar a cúria, tornando-a mais simples e eficiente, fazer limpeza no banco do vaticano e promover a colegialidade, instaurando consultas frequentes entre o papa, o colégio cardinalício e as conferências episcopais nacionais (Politi 20I4).

Na entrevista a Antônio Spadaro da revista La Civiltà Cattolica, fazendo referência à reforma da Cúria e às competências dos dicastérios que a compõem, afirmou que estes "estão a serviço do papa e dos bispos: devem ajudar tanto as Igrejas particulares quanto as conferências episcopais [...] se forem mal entendidos, correm o risco de se tornar organismos de censura. Os dicastérios romanos são mediadores, não intermediares ou gestores" (Spadaro 20I3). De acordo com Politi (2OI4), isso já representaria uma revolução, pois 
o que era considerado até agora apenas um instrumento totalmente a serviço do papa, deverá se transformar em um mecanismo de ajuda e de ligação entre o papado e os episcopados do mundo.

Outro ponto abordado na entrevista foi a maior autonomia desejada pelo papa Francisco para as Conferências episcopais locais. Por exemplo, lembrando a quantidade de denuncias de falta de ortodoxia que chegam a Roma, Papa Francisco afirmou que "estes casos deveriam ser estudados pelas Conferências episcopais locais, às quais pode chegar uma ajuda válida de Roma. Os casos, de fato, se tratam melhor no lugar" (Spadaro 2013).

Tal decisão, se concretizada, constituiria uma ruptura com a postura adotada por Bento XVI. Com efeito, para Ratzinger as conferências nacionais não seriam parte integrante da estrutura da Igreja, cabendo-lhe apenas uma função pratica (Ratzinger 2000). Deste ponto de vista, Bento XVI defendia a manutenção de uma Igreja vertical de tipo imperial onde Roma ditava lei às sedes nacionais, enquanto o Papa Francisco está trabalhando para que a Igreja se torne uma instituição participativa, cuja atuação seja horizontal através de colaboração efetiva entre o governo central de Roma e as igrejas nacionais.

Em I3 de abril de 20I3, a exatamente um mês de sua eleição, Papa Francisco deu concretamente o primeiro passo em direção à tão esperada reforma da Cúria Romana: a criação de um grupo de oito Cardeais mais um Secretário com o objetivo de aconselhar o papa no governo da Igreja Católica e no projeto de revisão da Constituição Apostólica "Pastor Bonus", de I988, que regulamenta e estrutura o funcionamento da Cúria Romana.

Os Cardeais que integram o Conselho consultivo do papa são provenientes de todos os continentes e, com exceção do Governador do Estado da idade do Vaticano, o Cardeal Giuseppe Bertello, nenhum deles pertence à Cúria Romana. Após o ingresso no grupo do Secretário de Estado, Pietro Parolin, o grupo passou a ser chamado extraoficialmente de C9.

Desde sua criação, o Conselho se reúne a cada dois meses, na residência do papa, Casa Santa Marta. As reuniões duram três dias com a participação constante do papa. Após as primeiras reuniões, o Conselho chegou à conclusão que não vai ser suficiente reformar a Constituição "Pastor Bonus" de João Paulo II. Será preciso redesenhar "ex-novo o modelo de Cúria após séculos de poder ultra-centralizado". (Politi 20I4, I49).

\subsubsection{Renovação do Colégio Cardinalício}

Nos dois anos de pontificado, Papa Francisco nomeou 3I novos cardeais eleitores que vêm renovar o Colégio dos Cardeais da Igreja Católica. De 
acordo com o Cânone 349 do Código de Direito Canônico de I983, cabe ao Colégio dos Cardeais providenciarem a eleição do Romano Pontífice, além de assistir o papa "quer agindo colegialmente, quando forem convocados para tratar em comum dos assuntos de maior importância, quer individualmente, nos vários ofícios que desempenham, prestando auxílio ao Romano Pontífice na solicitude quotidiana da Igreja universal"3.

O Colégio dos Cardeais foi instituído em II50. O número dos cardeais integrantes cresceu com o passar dos séculos. No pontificado de Paulo VI foram estabelecidas regras quanto ao número máximo, estabelecido em I20, e quanto à idade máxima dos eleitores dispondo que ao cumprimento do $80^{\circ}$ ano, os Cardeais perdem o direito de entrar no Conclave. Mas o que chama mais a atenção na análise da criação dos cardeais eleitores durante os últimos pontificados é a proveniência geográfica destes cardeais. Durante os pontificados de João Paulo II e Bento XVI, a maioria dos cardeais eleitores veio da Europa, principalmente de nações próximas à região de origem dos pontífices, e os membros da Cúria Romana. Também neste caso, Francisco escolheu um caminho diferente. Os cardeais escolhidos pelo Papa Bergoglio vêm de todos os continentes, com evidente diminuição da percentagem dos europeus em relação aos pontificados que o precederemos como podemos visualizar nos gráficos que seguem.

\section{Cardeais criados por João Paulo II}

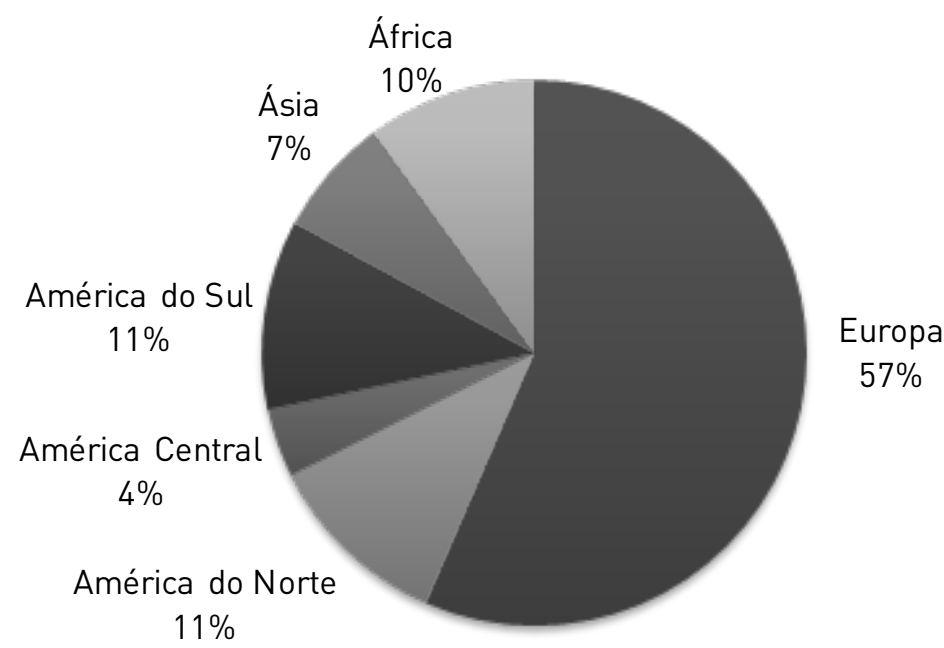

Fonte: http://www.vatican.va

3 Código de Direito Canônico. Disponível em: http://www.vatican.va/archive/cod-iuris-canonici/portuguese/codex-iuris-canonici_po.pdf. Acesso em: 27 mai. 2014. 
Cardeais criados por Bento XVI

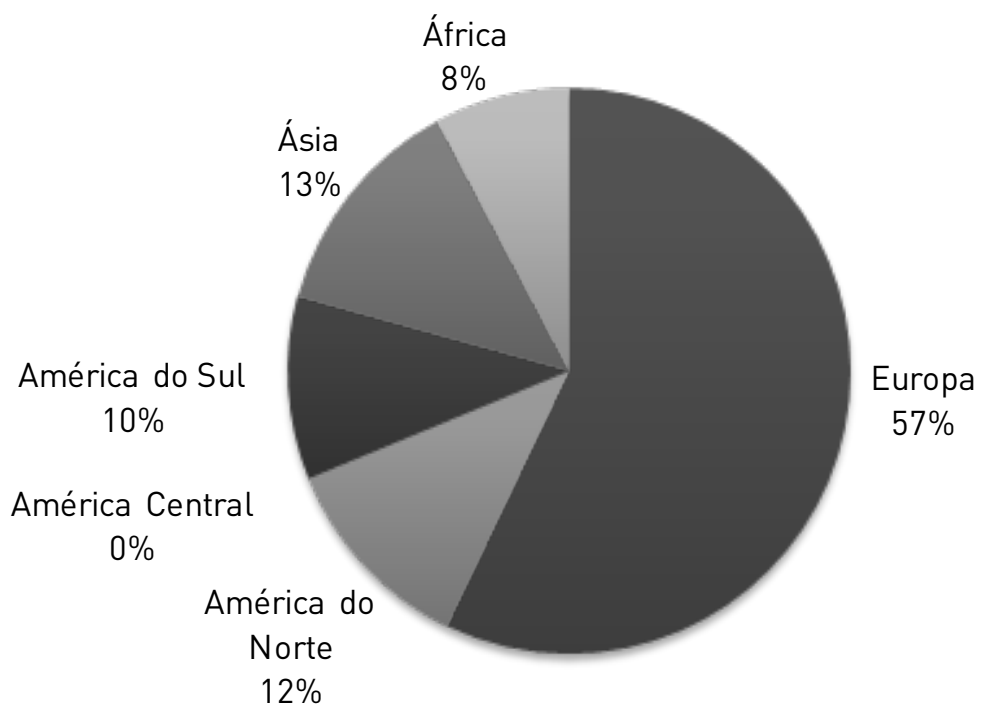

Fonte: http://www.vatican.va

\section{Cardeais criados por Francesco}

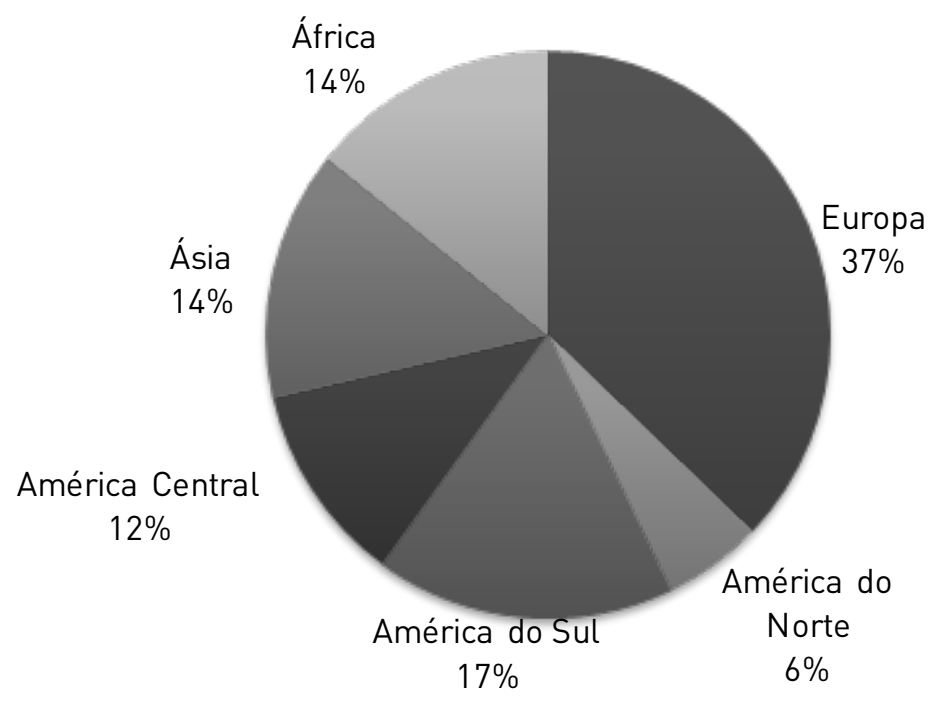

Fonte: http://www.vatican.va 
O gráfico que segue mostra a distribuição geográfica dos cardeais que compõem atualmente o Colégio Cardinalício.

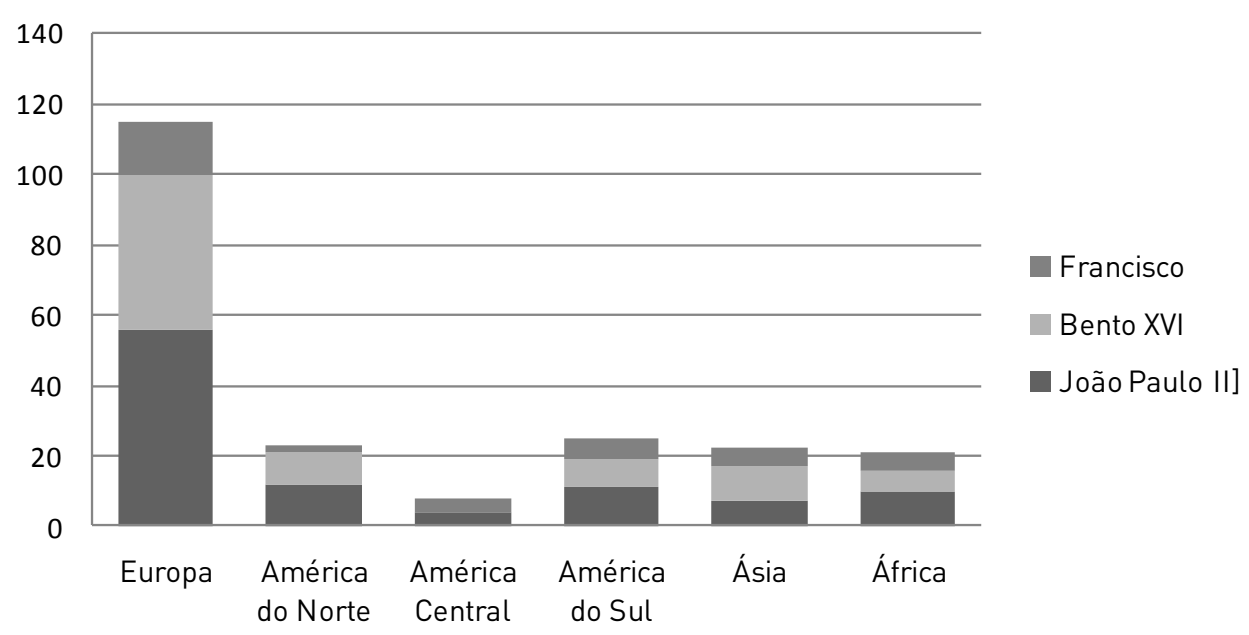

Fonte: http://www.vatican.va

Ainda há uma disparidade entre a Europa e os outros continentes, disparidade esta, que é o resultado da escolha feita sob os pontificados de João Paulo II e Bento XVI. Contudo, calcula-se que daqui a alguns anos o Papa Francisco deverá ter renovado mais da metade do corpo eleitoral do papa que o substituirá, deixando um Colégio de Cardeal mais representativo de todos os continentes onde o peso da Europa e, sobretudo o domínio tradicional dos italianos, deverá diminuir de forma considerável. De acordo com Politi "o futuro do catolicismo já não está mais no velho continente, mas entre os povos do Terceiro mundo. O pontífice reforçou particularmente a componente da América Latina, onde vive quase a metade dos católicos do planeta" (Politi 20I4, 238).

\subsubsection{Mudanças revolucionárias no papado e na Igreja Católica}

Desde o início de seu pontificado, Papa Francisco mostrou que o caminho que iria escolher seria de mudança, a começar pelo nome que nunca fora escolhido antes por nenhum papa. Além disso, Bergoglio se recusou em ser chamado Francisco I, provavelmente porque esta numeração ao lado do nome pode lembrar mais uma dinastia imperial que o título de um chefe religioso. Por último, ele deixou claro que o nome escolhido não se referia tanto ao missionário espanhol jesuíta Francisco Xavier que conquistou a Ásia, quanto a Francisco de Assis, o santo que desafiou a rica e corrupta Igreja 
Medieval apresentando-se como representante de uma igreja extremamente despojada de riquezas e de títulos.

As referências à pobreza como característica indispensável da Igreja Católica e de seus representantes são elementos constantes nos documentos oficiais do Papa Francisco desde 20I3, ano de sua eleição.

A reforma do IOR (Instituto para as Obras da Religião), conhecido mais popularmente como banco do Vaticano, é considerada um dos primeiros passos dado pelo novo papa em direção à reforma do Vaticano. Tal reforma - iniciada já no primeiro ano de seu pontificado - está sendo caracterizada pela busca de limpeza total nos movimentos financeiros do Vaticano, pelo aumento da transparência e pela mudança de diretores que se envolveram em escândalos.

Ainda no final de 2013, Papa Francisco instituiu um Conselho para a Economia criado para vigiar a gestão econômica e a atividade administrativa e financeira de todas as estruturas da Santa Sé. O Conselho é constituído por oito bispos e sete profissionais leigos. O presidente é o Cardeal de Munique, Reinhard Marx, também membro do C9 que auxilia o papa no governo da igreja Católica.

Além da reforma das finanças, o estilo de condução da Igreja Católica e de seus representantes parece estar sob acusação no novo pontificado.

Já em sua primeira visita internacional ao Brasil, o Papa Francisco dirigindo-se aos bispos responsáveis do Conselho Episcopal Latino-Americano (CELAM), chamou atenção para o perigo do clericalismo evidenciando as características que os bispos deveriam apresentar.

Os Bispos devem ser Pastores, próximos das pessoas, pais e irmãos, com grande mansidão: pacientes e misericordiosos. Homens que amem a pobreza, quer a pobreza interior como liberdade diante do Senhor, quer a pobreza exterior como simplicidade e austeridade de vida. Homens que não tenham "psicologia de príncipes". (Papa Francisco 20I3).

No final de 20I4, o discurso do Papa Francisco aos Cardeais e Bispos da Cúria Romana, ganhou destaque na mídia internacional. O papa aproveitou da oportunidade de se reunir com Cardeais e Bispos da Cúria Romana, em ocasião do Natal, para apresentar-lhe uma lista das quinze doenças que afetariam a Cúria Romana. Entre elas, o papa destacou a doença de se sentir imortais, a da excessiva operosidade, a do endurecimento mental e espiritual, do excessivo planejamento, a doença do Alzheimer espiritual, da rivalidade e da vanglória, da esquizofrenia espiritual, das fofocas, da indiferença e da 
acumulação, dos círculos mundanos, do lucro mundano e dos exibicionismos entre outras (Papa Francisco 20I4). Após o discurso, reuniu-se com os funcionários do Vaticano e seus familiares aos quais apresentou seu pedido de perdão: "Não quero terminar este encontro de bons votos sem vos pedir perdão pelas faltas, minhas e dos meus colaboradores, e também por alguns escândalos, que fazem muito mal. Perdoai-me." (Papa Francisco, 20I4).

O diagnostico da Cúria Romana, traçado com tanta clareza por Papa Francisco naquela ocasião, lhe atraiu críticas não apenas no território do Vaticano, como também nos ambientes mais conservadores do catolicismo italiano e internacional.

Sua rebelião em abraçar o estilo de vida de seus predecessores foi considerada um atentado à tradição que sustentou o papado ao longo de sua história. Os mais conservadores a interpretaram como uma crítica aos pontífices que o precederam, uma crítica ao modelo de Igreja tradicional compreendida como intocável estrutura central de poder da Igreja católica. Teme-se que Francisco, com sua simplicidade, possa diminuir a sacralidade da pessoal papal (Politi 20I4).

Sempre de acordo com Politi $(2014,232)$ "remodelar e simplificar a cúria significaria em perspectiva uma perda de poder, de influência de carreira e também de dinheiro de certa classe burocrático-eclesiástica, que se perpetua há séculos".

As críticas que os cardeais e bispos pertencentes a este grupo não podem manifestar abertamente, são veiculadas através de inúmeros sites e jornais tanto italianos que estrangeiros.

Não obstante os contínuos ataques dos meios de comunicação, o Papa Francisco parece estar avançando com decisão e firmeza, mesmo tendo ciência que os anos de seu pontificado - que seus opositores desejam seja breve - não serão suficientes para finalizar as reformas necessárias para mudar o rumo de uma Igreja até agora guiada por princípios monárquicos.

Uma das estratégias que o Papa Francisco parece estar usando é a de se circundar de pessoas competentes e profissionais em sua área de atuação que o ajudem a tornar tais mudanças eficazes e elevem o nível de preparação e atuação dos representantes da Igreja Católica. Exemplo disso, a constituição do C9, do qual falamos anteriormente e a mudança de seus colaboradores naquela é considerada uma das mais importantes áreas de atuação da Santa Sé, a dimensão internacional do papado.

Tal dimensão está adquirindo mais visibilidade justamente pelo deslocamento ideológico do Papa Francisco, cuja atenção está voltada mais às periferias do planeta que aos centros tradicionais de poder. 


\subsection{A nova diplomacia do Papa Francisco}

A escolha da proveniência geográfica dos novos cardeais parece demonstrar uma especial atenção do papa em garantir um maior equilíbrio entre centro e periferias. Mesmo sendo ainda alto o número de cardeais da Europa, com o tempo a tendência parece ser aquela de fortalecer a contribuição das "periferias" contrabalanceando o peso até então tido pela Cúria Romana e pela Igreja Europeia. Fortalecendo as Igrejas locais, se garantiria uma maior descentralização das relações de força na própria Igreja Católica, uma demanda que remonta ao Concílio Vaticano II, mas que até agora tinha ficado apenas no papel.

Reforça esta hipótese a análise das metas das viagens realizadas pelo papa nestes dois anos e meio de pontificado. Ao listar as metas internacionais já visitadas: Brasil, Turquia, Albânia, Coreia do Sul, Terra Santa, Sri Lanka e Filipinas, Bósnia-Herzegovina, Equador, Bolívia, Paraguai e a próxima visita a Cuba, se tem a impressão que a predileção do Papa Francisco em relação às periferias do mundo não permaneceu só na retórica. Os países que ele visitou são países que estão ou na periferia da Europa, ou na região chamada de sul do mundo, caracterizada por um passado ou presente de conflitos ou/e de exclusão, ou de marginalização do centro mundial político ou econômico.

As próprias visitas na Itália foram realizadas, na sua maioria em cidades ou cidadezinhas periféricas. Se observarmos com atenção a maneira de agir ou de falar do Papa Francisco nota-se que desde o início ele escolheu certa forma de governar: poucos colaboradores, mas bem formados que o auxiliem a ver e entender o panorama internacional em que a Igreja Católica está inserida para que ele possa tomar a decisão final. Entre estes colaboradores, a escolha do Secretário de Estado de um papa é considerada uma das mais estratégicas para o sucesso de um pontificado. A figura do Secretário de Estado corresponde na Santa Sé ao Primeiro Ministro ou ao Ministro das Relações Exteriores dos outros Estados.

Durante o pontificado de Bento XVI, por exemplo, a figura de seu Secretário de Estado, Tarciso Bertone sofreu bastante desgaste e não ajudou o já complexo pontificado de Bento XVI.

O novo Secretário de Estado do Papa Francisco não é um canonista como Tarcisio Bertone, mas um diplomata experiente que, Francisco, talvez não por acaso foi buscar na sua região de origem, a América do Sul.

Pietro Parolin, italiano, nascido em I955, quando chamado pelo Papa Francisco, encontrava-se na Venezuela onde, desde 2009, exercia as funções de Núncio Apostólico. Chegara na Venezuela após ter acumulado bastante 
experiência internacional. Além das experiências na Nigéria e no México, Parolin trabalhou io anos na Secretária de Estado durante os quais aprofundou seu conhecimento das principais questões geopolíticas do continente asiático: o conflito Palestina/Israel e as delicadas relações com o Vietnã. Criado Cardeal em 20I4, pelo Papa Francisco, participa regularmente das reuniões do Conselho de Cardeais (C9).

Para entendermos os pontos-chave do pensamento diplomático de Papa Francisco, escolhemos três documentos que manifestam tal pensamento, a saber, as duas Lectio Magistralis, proferidas em nome do papa pelo Cardeal Parolin, respectivamente em março de 20I5, na Pontifícia Universidade Gregoriana de Roma e, em abril de 20I5, na Faculdade de Teologia do Triveneto, mais a Exortação Apostólica Evangelii Gaudium, escrita por Papa Francisco em 20I3, quase um manifesto de intenções sobre o futuro de seu pontificado.

Na Lectio Magistralis proferida em março, abordando os objetivos da ação diplomática da Santa Sé, o Secretário de Estado primeiramente sublinha a postura pró-ativa da diplomacia da Santa Sé quando afirma que "ela não pode se contentar do papel de voz crítica, sendo chamada a atuar para facilitar a coexistência e a convivência entre as várias nações" (Parolin 20I5).

Para que a Santa Sé possa ter os meios adequados para que esta atuação seja efetiva e incisiva, Papa Francisco, propôs que no espaço da Secretaria de Estado volte a funcionar um Escritório para a mediação pontifícia que funcione de elo entre as atividades que a diplomacia da santa Sé já desempenha em diferentes países e também se coligar às atividades que desempenham neste âmbito as Instituições Internacionais. Nos anos 80, durante o pontificado de João Paulo II foi criado este Escritório dentro do Conselho para os Assuntos Públicos, que hoje é conhecida como Secção para as relações com os Estados da Secretaria de Estado. A tarefa deste Escritório era desenvolver conteúdos jurídicos-políticos que auxiliassem na resolução da disputa territorial entre a Argentina e Chile sobre o Canal de Beagle, no extremo sul do Continente americano.

A função de arbitragem e mediação pode ser considerada uma das atuações tradicionais ao longo da história da Santa Sé e de suas relações com os países. Parolin lembrou que estas mediações estão profundamente ligadas à dimensão eclesial, justamente porque foi pela presença e pelo papel da Igreja nos países diretamente interessados que a intervenção diplomática da Santa Sé foi considerada essencial (Parolin 20I5).

No mês seguinte, Parolin proferiu nova Lectio Magistralis dessa vez dirigida à comunidade acadêmica da Faculdade de Teologia do Triveneto, durante a qual evidenciou a visão do papa frente aos desafios do mundo atual. Muitos dos elementos desta conferência coincidem com os temas tratados 
pelo papa na Exortação Apostólica Evangelii Gaudium.

De acordo com Parolin, a visão que o Papa Francisco tem do mundo é a de um mundo aberto, onde em princípio não existem situações ou costumes pré-constituídos.

Este Papa que vem de longe, do fim do mundo, como ele disse no dia de sua eleição, olha à Europa e ao mundo com um olhar diferente, descentrado e distante daquela visão que acompanha a tradicional leitura teológica. Ele não pertence nem ao Oriente, nem ao Ocidente, como também não provém do coração do sistema internacional; por isso seu ensinamento desconcerta nossa habitual perspectiva e de certa forma revira nossa forma de ver o mundo e a Igreja. Como bom jesuíta, ele exerce seu discernimento e se coloca na busca da vontade de Deus para perscrutá-la e assim se preparar a tomar decisões sobre a terra: o que há de mais geopolítico e teológico ao mesmo tempo? (Parolin 20I5).

Ser o primeiro papa não europeu, e o primeiro papa latino-americano, certamente influencia a visão e abordagem dada por Bergoglio ao seu pontificado.

Ele não possui a dívida moral que os europeus assimilaram voluntariamente ou involuntariamente em relação aos Estados Unidos, como consequência dos horrores dos dois Conflitos Mundiais. Ao contrário ele viveu em sua própria pele o duro impacto da política de Segurança atuada pela superpotência norte-americana na América Central e América do Sul durante o período da Guerra Fria. Tais experiências possibilitam ao pontificado de Francisco um olhar diferente não do centro às periferias como foi o olhar tradicional dos papas que o precederam, mas das periferias ao resto do mundo. Foge à abordagem de Francisco a possibilidade de se aliar a um país hegemônico para levar para frente os objetivos da Igreja Católica, como aconteceu em diferentes papados. A preferência de Francisco parece ser um mundo multipolar onde as diferenças ao invés de dividir podem acrescentar e potencializar a busca das nações periféricas por um mundo menos desigual.

De acordo com Parolin, no novo pontificado de Francisco

(...) as periferias devem estar no centro das preocupações dos países que por condição social, política, econômica, territorial são os protagonistas do sistema internacional, como também das instituições internacionais chamadas a programar e gerenciar a cooperação e às suas ações. Somente englobando as periferias é possível ativar programas e ações inspirados pela solidariedade e não finalizados à assistência (Parolin 20I5). 
E para alcançar os excluídos, as periferias, a diplomacia da Santa Sé é considerada um instrumento privilegiado.

Se os governos realizam aquela que é chamada a "razão de estado" exercitando um Hard Power através da potência econômico-financeira ou das armas, a Santa Sé deve levar a cabo uma "razão da Igreja" através de um Soft Power feito de conviç̧ões e de comportamentos exemplares. Ela deve trabalhar, também através da ação diplomática, para criar mais justiça, primeira condição da paz (Parolin 20I5).

\subsection{Papa Francisco e os ataques ao capitalismo}

O tema da justiça social é outro argumento recorrente nos documentos do papa Francisco. A Exortação Apostólica Evangelii Gaudium de 2013 - e a Enciclíca sobre a questão ambiental, Laudato Sí, publicada há algumas semanas, apresentam fortes críticas ao atual sistema econômico cujas contradições são apontadas pelo Papa Francisco como as causas mais profundas dos problemas da sociedade de hoje. Papa Francisco não hesita em afirmar que "o sistema social e econômico é injusto na sua raiz” (PAPA FRANCISCO, 20I3, p. 50).

Assim como em Buenos Aires Bergoglio criticava a corrupção do governo argentino, como papa, hoje ele crítica o sistema mundial apoiado unicamente numa lógica de mercado.

Não podemos mais confiar nas forças cegas e na mão invisível do mercado. O crescimento equitativo exige algo mais do que o crescimento econômico, embora o pressuponha; requer decisões, programas, mecanismos e processos especificamente orientados para uma melhor distribuição das entradas, para a criação de oportunidades de trabalho, para uma promoção integral dos pobres que supere o mero assistencialismo. Longe de mim propor um populismo irresponsável, mas a economia não pode mais recorrer a remédios que são um novo veneno, como quando se pretende aumentar a rentabilidade reduzindo o mercado de trabalho e criando assim novos excluídos. (Ibid, I68)

A solidariedade é apontada por Francisco como elemento fundamental que deve estar presente nas relações mundiais, e antídoto ao atual sistema econômico que gera exclusão, pobreza e cultura do descarto junto à maioria da população mundial. 
Enquanto os lucros de poucos crescem exponencialmente, os da maioria situam-se cada vez mais longe do bem-estar daquela minoria feliz. Tal desequilíbrio provém de ideologias que defendem a autonomia absoluta dos mercados e da especulação financeira. Por isso, negam o direito de controle dos Estados, encarregados de velar pela tutela do bem comum. Instaura-se uma nova tirania invisível, às vezes virtual, que impõe, de forma unilateral e implacável, as suas leis e as suas regras. (Ibid, 50)

Na Encíclica Laudato Sí, após elencar os problemas mais graves relacionados ao degrado do meio ambiente, Papa Francisco evidencia a profunda ligação entre o degrado ambiental e as condições de pobreza e injustiça social que afetam ainda a maioria da população mundial, e que resulta numa situação de desigualdade planetária. Com efeito, de acordo com Papa Francisco, não existiria apenas desigualdade entre os indivíduos, mas também entre os países, o que obrigaria a pensar numa ética das relações internacionais para refletir sobre a dívida "ecológica" que existe entre o Norte e o Sul.

A dívida externa dos países pobres transformou-se num instrumento de controle, mas não se dá o mesmo com a dívida ecológica. De várias maneiras os povos em vias de desenvolvimento, onde se encontram as reservas mais importantes da biosfera, continuam a alimentar o progresso dos países mais ricos à custa do seu presente e do seu futuro. A terra dos pobres do Sul é rica e pouco contaminada, mas o acesso à propriedade de bens e recursos para satisfazerem as suas carências vitais é-lhes vedado por um sistema de relações comerciais e de propriedade estruturalmente perverso (Papa Francisco 2015, 52-52).

Numa entrevista ao Papa Francisco, de janeiro de 20I4, o papa defende suas críticas ao sistema neoliberal ressaltando a necessidade urgente de operar mudanças estruturais.

Não podemos mais esperar para resolver as causas estruturais da pobreza, para curar as nossas sociedades de uma doença que só pode levar a novas crises. Os mercados e a especulação financeira não podem gozar de uma autonomia absoluta. Sem uma solução aos problemas dos pobres não resolveremos os problemas do mundo. São necessários programas, mecanismos e processos orientados a uma melhor distribuição dos recursos, à criação de trabalho, à promoção integral de quem está excluído. (Francisco apud Tornielli 20I5) 
Por estas ferrenhas críticas ao atual sistema econômico, Papa Francisco foi acusado pelos ambientes conservadores de ser comunista e próximo à Teologia da Libertação. Quando lhe perguntaram se tais acusações o perturbaram, Papa Bergoglio respondeu que a opção preferencial aos pobres está contida desde o início na mensagem evangélica.

Se eu repetisse alguns trechos das homilias dos primeiros Padres da Igreja, do segundo ou terceiro século, sobre como se deve tratar os pobres, haveria alguns que acusariam que a minha homilia é marxista. "Não é dos teus bens que tu doas ao pobre; tu só lhe devolves o que lhe pertence. Porque é àquilo que é dado em comum para o uso de todos que tu te apegas. A terra é dada a todos, e não somente aos ricos". São palavras de Santo Ambrósio, que serviram para que o Papa Paulo VI afirmasse, na Populorum progressio, que a propriedade privada não constitui para alguns um direito incondicional e absoluto, e que ninguém está autorizado a reservar para o seu uso exclusivo aquilo que supera a sua necessidade, quando aos outros falta o necessário. São João Crisóstomo afirmava: "Não compartilhar os próprios bens com os pobres significa roubá-los e privá-los da vida. Os bens que possuímos não são nossos, mas deles". (Francisco apud Tornielli 20I5)

A postura adotada pelo Papa Francisco, neste sentido, aparece revolucionária em relação à atitude tradicional da Igreja Católica e do papado. É verdade que também em documentos anteriores do Papa João Paulo II e Bento XVI podem ser encontradas críticas ao sistema econômico neoliberal. O próprio Papa Francisco as coloca em evidencia tanto na Exortação Apostólica Evangelii Gaudium quanto na Encíclica Laudato Sí. Contudo, tais críticas podem ser consideradas referências isoladas dentro de pontificados que não se destacaram por grandes mudanças e oposição ao sistema econômico vigente. Papa Francisco não perde ocasião para chamar atenção sobre as causas estruturais que geram pobreza, violência e desigualdade planetária. O apelo á mudança pode ser encontrado em todos os documentos e discursos pronunciados desde o início de seu pontificado.

\section{Conclusões}

Ao longo deste artigo, procuramos verificar a hipótese de que, nestes dois primeiros anos do pontificado, o Papa Francisco estaria realizando um deslocamento ideológico da Santa Sé, aproximando a estrutura central da Igreja Católica, tradicionalmente ligada às elites nacionais e internacionais, às periferias do mundo político e eclesial. 
Os passos dados por Francisco durante este período de dois anos e meio parecem contribuir à descentralização do poder até então restrito à Cúria Romana. Além disso, muitas decisões importantes tomadas pelo Papa Bergoglio, que por questões de limitação de espaço não foram tratadas neste trabalho, demonstraram uma tentativa de mudança de rumo por parte do Papa Francisco. Citamos por exemplo: a criação dos Encontros Mundiais dos Movimentos Sociais e o incentivo dado pelo Papa Francisco à luta deste setor da sociedade; a beatificação de Dom Oscar Romero, após anos de silêncio por parte da Santa Sé que o considerava próximo demais à esquerda de El Salvador; a reabilitação de padre Miguel d'Escoto, o sacerdote que se tornou, na década de I970, ministro das Relações Exteriores do governo sandinista e que por isso foi suspenso das suas funções sacerdotais por 29 anos; a mediação pontifícia entre Cuba e Estados Unidos, o reconhecimento formal do Estado da Palestina, entre os acontecimentos internacionais de maior relevo. De acordo com Cardini, Francisco

(...) como peronista tem uma visão social muito avançada, quase socialista. Para ele a ordem social é justiça social, solidariedade, amor e resgate dos últimos. Não é por acaso que Francisco condena sempre a economia, nunca diretamente a política. Ele quer que a sociedade retorne a um modelo de cristianismo puro, como o frei de Assis que se despojou de tudo. Só que na Idade Média o contexto era integralmente cristão. Bergoglio quer ao contrário derrubar a ordem constituída, reverter o rumo do progresso socioeconômico do turbocapitalismo. Aqui está sua revolução, o apocalipse (Cardini apud Ciolli 20I4).

\section{REFERÊNCIAS}

Ciolli, Barbara. 20I4. "Papa Francesco, La política estera del pontefice." Lettera43, August 22, 2014. Accessed October Io, 2014. http:// www.lettera43.it/politica/papa-francesco-la-politica-estera-delpontefice_43675138538.htm.

Dosdad Iranzo, Àngela. 2006. "Religión y Relaciones Internacionales Genealogías.” Foro Interno (6): 39-65.

Fox, Jonathan. 2006. "Religion et relations internationales: perceptions et réalités.” Politique Étrangère (4) (Hiver). http://www.cairn.info/revuepolitique-etrangere-2006-4-page-I059.htm

Ferrara, Pasquale. 20I4. Atlante teopolitico: religioni e relazioni internazionali. Roma: Città Nuova.

Francisco. 2013. Evangelii Gaudium: Exortação Apostólica sobre o anúncio do 
evangelho no mundo atual. Roma: Libreria Editrice Vaticana.

. Discurso aos Bispos Responsáveis do Conselho Episcopal Latino-Americano (C.E.L.A.M.), Rio de Janeiro, 28 de julho de 2013. Accessed May Io, 20I4. http://w2.vatican.va/content/francesco/pt/speeches/20I3/july/ documents/papa-francesco_20130728_gmg-celam-rio.html.

. Discurso no Encontro com os Cardeais e Colaboradores da Cúria Romana para a Troca de Bons Votos de Natal. Segunda-feira, 22 de Dezembro de 2014. Accessed April 20, 2015. http://w2.vatican.va/content/francesco/ pt/speeches/20I4/december/documents/papa-francesco_2OI4I222_ curia-romana.html.

. Encontro com todos os Funcionários do Estado da Cidade do Vaticano e respectivos Familiares. Sala Paulo VI, 22 de dezembro de 2014. Accessed April 20, 20I5. http://w2.vatican.va/content/francesco/pt/speeches/20I4/ december/documents/papa-francesco_20I4I222_dipendenti-santasede-scv.html.

. Laudato Sí: Encíclica sobre o cuidado da casa Comum, 24 de maio de 2015. Accessed May 30, 20I5. http://w2.vatican.va/content/francesco/pt/ encyclicals/documents/papa-francesco_20I50524_enciclica-laudato-si. html.

Frattini, Eric. 20I4. La CIA in Vaticano. Milão: Sperling \& Kupfer.

Haynes, Jeffrey. 2009. "Transnacional Religious Actors and International Order." Perspectives 17 (2): 43-70. Accessed July IO, 20I4. mercury.ethz. ch/.../Files/.../02_ogchapter3.pdf.

Politi, Marco. 20I4. Francesco tra i lupi: il segreto di una rivelazione. Roma-Bari: Editori Laterza.

Petito, Fabio, and Paulos Hazopoulos. 2003. Religion in International Relations: the return from exile. Palgrave MacMilian.

Parolin, Pietro. 2015. "Lectio Magistralis" del Cardinale Segretario di Stato al "Dies Academicus" della Pontificia Università Gregoriana. March 11, 2015. Accessed April 23, 2015. http://press.vatican.va/content/salastampa/ pt/bollettino/pubblico/20I5/03/II/oI78/00402.html

" "Lectio Magistralis" del Cardinale Segretario di Stato al "Dies Academicus" della Facoltà Teologica del Triveneto. April 4, 20I5. Accessed May Io, 20I5. http://www.fttr.it/fttr/allegati/I988/FTTR_20I5_04_24_ dies_academicus_prolusione_Parolin.pdf

Ratzinger, Jospeh. 2000. Presentazione del Motu Proprio Apostolos suos. July 27, 2000. Accessed July 23, 20I4. http://www.documentacatholicaomnia. eu/o4z/z_2000-07-27__Ratzinger._Joseph._Card__ 
Presentazione_'Apostolos_Suos'_IT.doc.html

Spadaro, Antonio. 2013. "Intervista a Papa Francesco." La Civiltà Cattolica. September I9, 2013. Accessed November I2, 20I4. https://w2.vatican. $\mathrm{va/content/francesco/it/speeches/20I3/september/documents/papa-}$ francesco_20I3092I_intervista-spadaro.html.

Tornielli, Andrea. 20I5. "Intervista a papa Francesco: Avere cura di chi è povero non è comunismo, è Vangelo". La Stampa. January II, 2015. Accessed February I4, 20I5. http://www.lastampa.it/20I5/OI/II/ italia/cronache/avere-cura-di-chi-povero-non-comunismo-vangelolasvmlIioCWdmIomYzig2J/pagina.html.

Turzi, Mariano. 20I3. "El Papa del tercer mundo." Foreign Affairs Latinoamérica I3 (3), I9-25. Accessed April 20, 20I4. www.fal.itam.mx.

\section{RESUMO}

Através de uma leitura internacional dos primeiros anos de pontificado de Francisco, associada à análise do contexto mundial e regional - com especial ênfase na conjuntura da América Latina - que o precedeu, buscar-se-á, nesta pesquisa, evidenciar a importância do papel que a Santa Sé pode desempenhar neste atual momento de reconfiguração mundial, não apenas em âmbito religioso, como também político. Tal estudo busca contribuir também para a construção de novas categorias conceituais aptas a explicar a noção de ator religioso transnacional e sua atuação no âmbito de um sistema internacional considerado pela maioria das teorias de relações internacionais como um sistema secularizado e com pouco espaço para o fenômeno religioso.

\section{PALAVRAS-CHAVE}

Santa Sé; Diplomacia; Ator Transnacional.

Recebido em 10 de julho de 2015. Aprovado em 2 de agosto de 2015. 